Revista Perspectivas Online: Exatas \& Engenharia Abril de 2019, v.09, n.24, p. 34-56 ISSN: 2236-885X (Online) DOI: $10.25242 / 885 X 92420191729$

\title{
ANÁLISE E PROPOSTA DE MELHORIAS NA ARBORIZAÇÃO DE UMA AVENIDA DO MUNICÍPIO DE CAMPOS DOS GOYTÁCAZES, RJ
}

\author{
Carlos Eduardo de Souza ${ }^{1 *}$, Ítalo de Oliveira Matias ${ }^{1}$ \& Milton Erthal Junior ${ }^{1}$
}

\section{RESUMO}

SOUZA, C.E.; MATIAS, I.O.; JUNIOR, M.E. Análise e proposta de melhorias na arborização de uma avenida do município de Campos dos Goytacazes, RJ. Perspectivas Online: Exatas \& Engenharia, v.09, n.24 , p. 34-56, 2019.

A arborização é um elemento relevante para minimizar os impactos causados pela urbanização desordenada. O objetivo da pesquisa foi de analisar e propor melhorias para arborização viária em avenida no município de Campos dos Goytacazes, RJ. Com base na literatura especializada, as espécies de plantas foram identificadas e propôs-se, na via onde o estudo de caso foi conduzido, melhorias para a arborização local. Foram identificadas 245 plantas, pertencentes a 37 espécies, dentre as quais cerca de $40 \%$ são nativas do estado de Rio de Janeiro. Mais de $20 \%$ das plantas são aroeiras, Schinus terebinthifolius, o que não é recomendado. Entre as plantas exóticas, algumas são inapropriadas para arborização urbana, como a Leucaena leucocephala e Nerium oleander. Constatou-se baixa densidade arbórea, além de muitas inconsistências na arborização da área de estudo, como a presença de plantas em locais inapropriados, espécies exóticas, muitas delas consideradas invasoras, plantas tóxicas ou inadequadas para arborização viária. Uma proposta de arborização foi elaborada para sanar os problemas diagnosticados. Em suma, a arborização da via se encontra ineficiente, além disso, constatou-se a necessidade de planejamento e elaboração de regras que visem a implantação e manejo adequado da arborização municipal.

Palavras-chave: Arborização viária; Planejamento; Proposta de arborização. 


\begin{abstract}
Afforestation is a relevant element to minimize the impacts caused by disordered urbanization. The objective of the research was to analyze and propose improvements for roadside reforestation in avenue in the municipality of Campos dos Goytacazes, RJ. Based on the specialized literature, the plant species were identified and in the path where the case study was conducted, improvements for local afforestation were proposed. 245 plants belonging to 37 species were identified, of which about $40 \%$ are native of the state of Rio de Janeiro. More than 20\% of the plants are aroeiras, Schinus terebinthifolius, which is not recommended. Among the exotic

plants, some are unsuitable for urban afforestation, such as Leucaena leucocephala and Nerium oleander. Low tree density was observed, in addition to many inconsistencies in the afforestation of the study area, such as the presence of plants in inappropriate sites, exotic species, many of them considered invasive, toxic or inadequate for road reforestation. A afforestation proposal was developed to solve the diagnosed problems. In short, afforestation of the road is inefficient, In addition, it was verified the need for planning and elaboration of rules aimed at the implantation and adequate management of municipal afforestation.
\end{abstract}

Keywords: Roadside reforestation; Planning; Proposal for afforestation.

${ }^{1}$ Universidade Cândido Mendes - Av. Anita Peçanha, 100, Parque São Caetano, Campos dos Goytacazes, RJ, CEP: 28030335, Brasil.

(*) e-mail: carlosedusouza@hotmail.com

Data de recebimento: 30/04/2019. Aceito para publicação: 07/06/2019.

Persp. Online: exatas \& eng., Campos dos Goytacazes, 24 (09) 34-56 - 2019

seer.perspectivasonline.com.br 


\section{INTRODUÇÃO}

Com o intuito de atender às próprias necessidades, o homem foi modificando o ambiente e, em alguns casos, de forma irreversível, substituindo os componentes naturais por artificiais. Um dos principais exemplos são os centros urbanos, que são ambientes totalmente modificados em relação à paisagem natural (ÁVILA; PANCHER, 2015).

No Brasil, 84,4\% da população reside em áreas urbanas (IBGE, 2017) e quase sempre a ocupação do território se dá de forma desordenada (OLIVA, 2016). O processo de urbanização, na maioria das vezes sem planejamento adequado, vem provocando inúmeras alterações no ambiente, incluindo a perda da vegetação natural, impermeabilização do solo, alagamentos, aquecimento dos ambientes e poluição do ar. No entanto, a vegetação intraurbana é considerada por muitos pesquisadores um indicador de qualidade ambiental, em razão de proporcionar melhorias ambientais, minimizando os impactos negativos da urbanização (BARGOS; MATIAS, 2012).

Quanto mais as cidades crescem, mais espaços livres são destinados às construções, ocupando os espaços onde poderiam existir a presença da arborização (VIGNOLIA JUNIOR, 2016). A presença das árvores eleva a permeabilidade do solo, controla a temperatura e a umidade do ar, intercepta a água da chuva, proporciona sombra, funciona como corredor ecológico, age como barreira contra o vento, ruído e alta luminosidade, diminui a poluição do ar, sequestra e armazena carbono e proporciona bem-estar psicológico (PREFEITURA DE SÃO PAULO, 2015). Além disso, os benefícios da arborização urbana se estendem para vida longa dos pavimentos e menores gastos com infraestrutura de drenagem (JAMES; MICHELCIC; AUER, 2015).

A arborização urbana é, portanto, um elemento importante ao favorecimento do equilíbrio ambiental e ajuda a proporcionar qualidade de vida à população urbana. Contudo, a eficiência da mesma vem sendo comprometida, devido à falta de planejamento na implantação e manejo inadequado das plantas (ALMEIDA; NETO, 2010).

Os espaços arborizados artificialmente têm que ser bem planejados, evitando conflitos com a infraestrutura existente (PREFEITURA DE SÃO PAULO, 2015). Para exemplificar estes conflitos, destaca-se o desenvolvimento do sistema radicular a ponto de danificar calçadas, conflito com fiações existentes, além da queda excessiva de folhas e frutos. Como resultado, transtornos, prejuízos e rejeição das árvores pela população (DOBBERT, 2015). Portanto, ruas arborizadas sem planejamento trazem prejuízos para o município, não atingindo os objetivos esperados (SCHUCH, 2006).

Para a implantação da arborização, destaca-se a preferência por espécies que apresentem porte arbóreo em relação às herbáceas (AZA, 2016). Além disso, também deve ser priorizado o uso de espécies nativas (POTENZA, 2016). As árvores nativas favorecem o ecossistema regional, oferecendo abundância e diversidade de alimento à fauna local, e também, melhoram os aspectos funcionais das comunidades (PENA et al., 2017). Por outro lado, entende-se que espécies exóticas invasoras podem afetar o ecossistema, devido a rusticidade, facilidade de desenvolvimento e propagação, provocando desequilíbrio dos processos ecológicos, ocupando os espaços de outras espécies, podendo até mesmo levar a extinção de espécies nativas (VIGNOLIA JUNIOR, 2016).

Persp. Online: exatas \& eng., Campos dos Goytacazes, 24 (09) 34-56 - 2019

seer.perspectivasonline.com.br 
A fim de que ocorra a integração da árvore com as pessoas, torna-se importante a destinação de espaço livre para acessibilidade. Além disso, não se recomenda o plantio de espécies produtora de substâncias tóxicas perigosas, que contenham espinhos que possam causar ferimentos em pessoas que transitam o local (ABNT, 2015).

Conhecer os aspectos biológicos das árvores como porte, arquitetura da copa, tipo de raízes e diâmetro máximo do tronco quando adulta se faz necessário. Os objetivos são de proporcionar desenvolvimento satisfatório da árvore, evitar conflitos com equipamentos urbanos e danos aos pavimentos, evitando, assim, operações de manejo, principalmente podas e transplante (PREFEITURA DE SÃO PAULO, 2015). Como resultado, produzirá uma arborização sustentável, com redução de custos e aceitação da população.

Com a expansão da área urbana do município de Campos dos Goytacazes (RJ), associado à falta de planejamento, muitos problemas surgiram e um dos quais se observa é a carência de arborização viária. Nesse contexto, o objetivo da pesquisa foi de analisar e propor melhorias para arborização em via do município em questão. Durante o artigo, as espécies arbóreas/arbustivas, local/região e frequência das espécies serão objeto de análise, ao se debater a importância de espécies adequadas ao local e em quantidades satisfatórias.

\section{METODOLOGIA}

A pesquisa foi pautada na fundamentação teórica e coleta de dados em campo. Ambas deram suporte para análise da arborização existente, bem como a proposta de melhorias da arborização da via. Além disso, a utilização de software CAD, na proposta de melhorias da arborização, possibilitou a análise integrada de toda área levantada.

\section{1. Área de estudo}

A pesquisa foi realizada no município de Campos dos Goytacazes, localizado no interior do Estado do Rio de Janeiro na mesorregião do Norte Fluminense. Maior município do interior do estado, com população estimada no ano de 2018 de 503424 habitantes, onde, 90,3\% da população mora na área urbana (IBGE, 2018).

A área selecionada para a pesquisa foi a avenida Senador José Carlos Pereira Pinto, localizada entre a avenida Francisco Lamego (RJ-194) e a avenida Professora Carmem Carneiro (paralela à BR 101), medindo $3,5 \mathrm{~km}$ de extensão, cortando diversos bairros do município. A figura 1 apresenta a localização da avenida Senador José Carlos Pereira Pinto, localização do trecho da via selecionado para proposta de melhorias na arborização e localização de pontos de seções transversais da pista, apresentadas na pesquisa.

Persp. Online: exatas \& eng., Campos dos Goytacazes, 24 (09) 34-56 - 2019 seer.perspectivasonline.com.br 


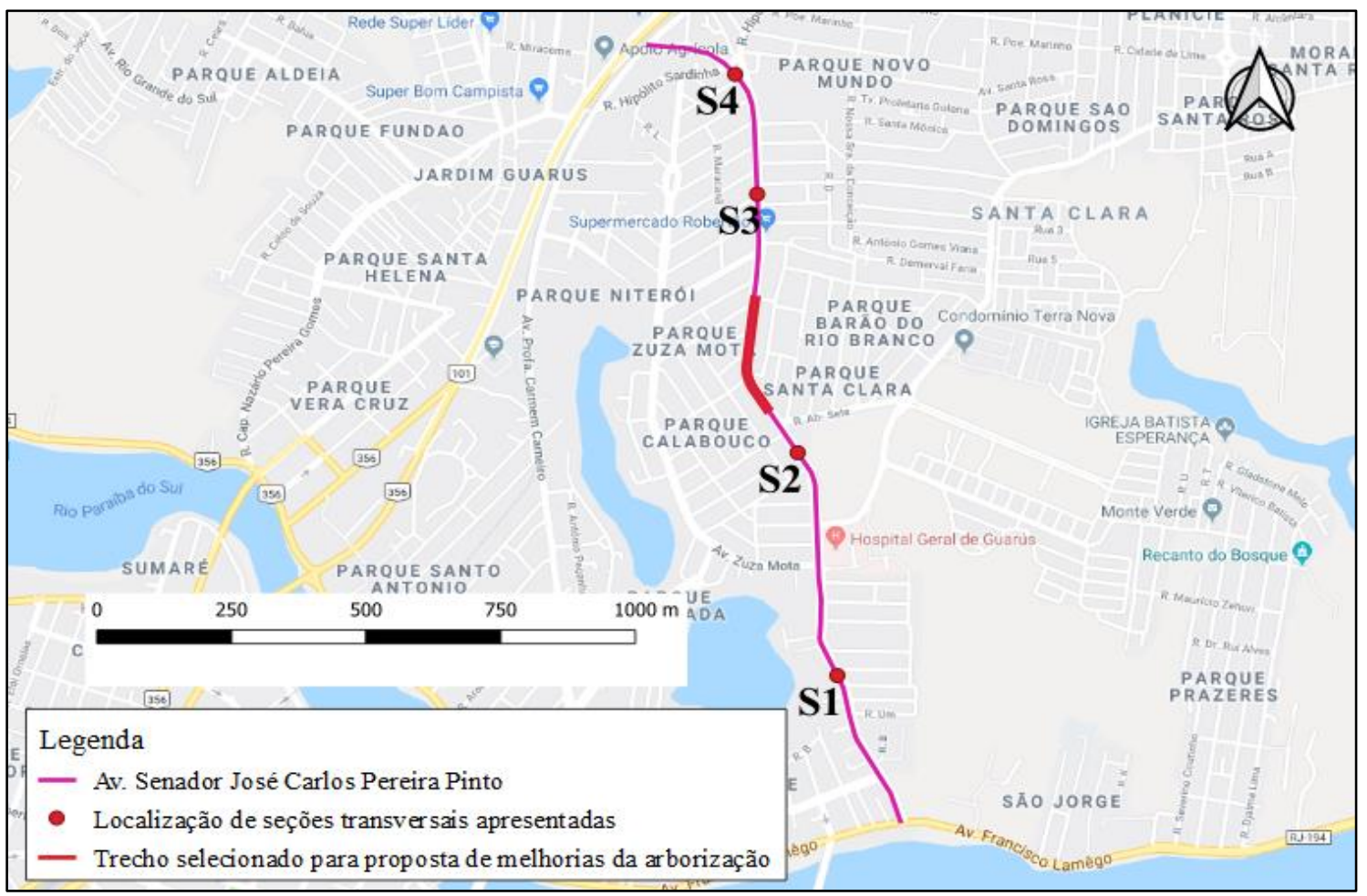

Figura 1: Localização da avenida Senador José Carlos Pereira Pinto, localização de quatro pontos de seções transversais (S1, S2, S3, S4) apresentadas na pesquisa e localização do trecho selecionado para proposta de melhorias na arborização. (Fonte: Google Maps, 2019, adaptado pelos autores).

Além disso, a avenida em estudo contém duas pistas, com duas faixas de rolamento em cada sentido, comporta uma ciclovia e área permeável no canteiro central, propiciando área para plantio de árvores (figura 2). Ademais, muitas pessoas utilizam a ciclovia para locomoção e atividades esportivas.

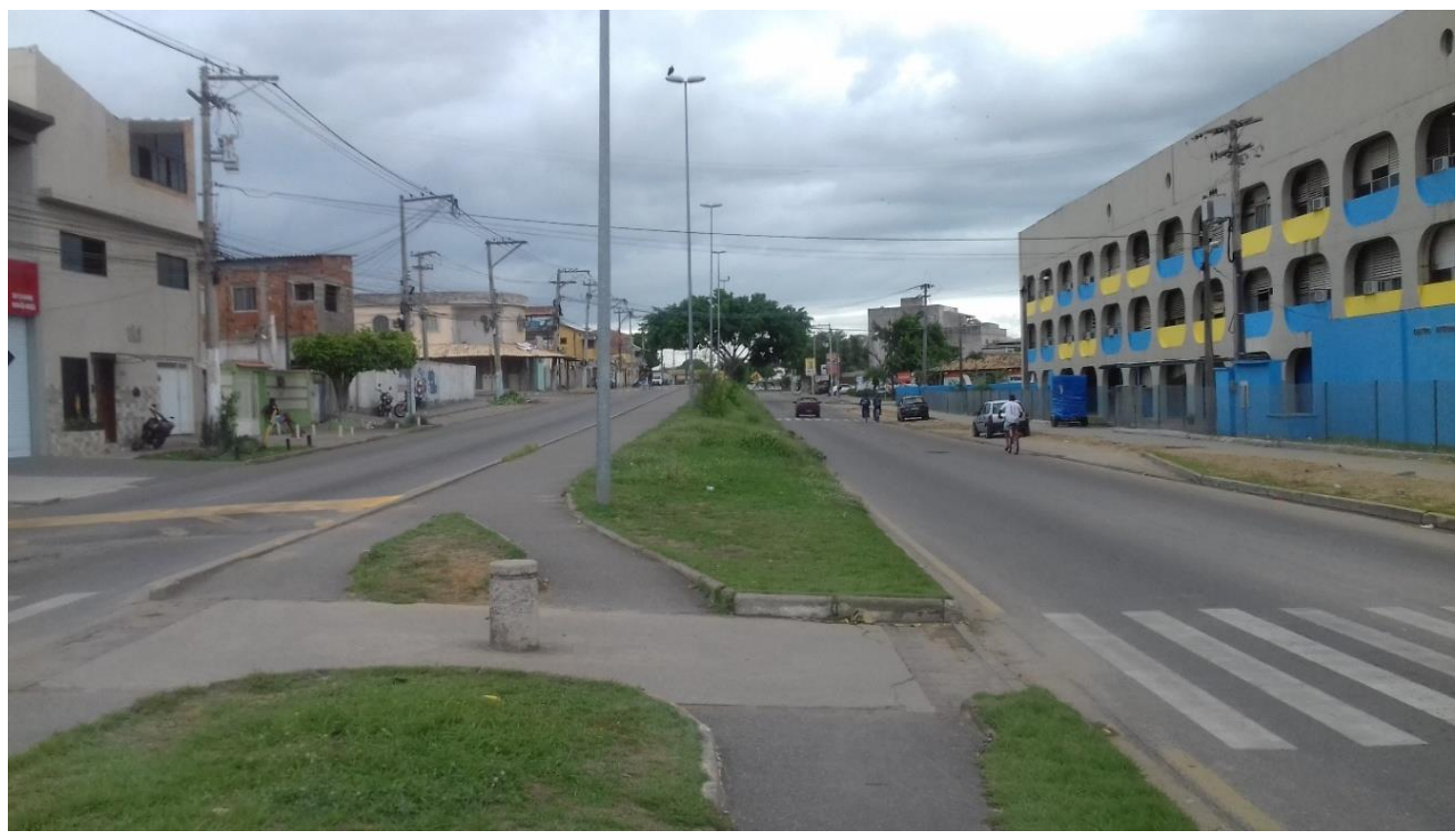

Figura 2: Avenida Senador José Carlos Pereira Pinto.

Persp. Online: exatas \& eng., Campos dos Goytacazes, 24 (09) 34-56 - 2019

seer.perspectivasonline.com.br 


\subsection{Análise da arborização viária existente}

Realizou-se levantamento bibliográfico para dar sustentação teórica e metodológica ao tema em estudo. Foi construído mapa de localização da área de estudo usando o Software QGIS versão 2.18.17 e com base cartográfica do Google Maps. Em seguida, realizou-se trabalho de campo nos meses de junho e julho de 2018. Neste contexto, foi levantado as medidas da avenida: larguras das pistas, calçadas, canteiro central e estacionamento empregando-se trena com fita de aço Starrett $30 \mathrm{~m}$. Ademais, a identificação das espécies arbóreas foi feita diretamente no levantamento de campo. Para tanto, contou-se com profissional especializado pertencente ao setor de arborização vinculado à secretaria de meio ambiente do referido município e com utilização de bibliografia específica Lorenzi et al. (2003), Lorenzi (2008), Lorenzi (2009) e Lorenzi (2013).

As espécies foram classificadas como nativa, com ocorrência no estado do Rio de Janeiro, e exóticas, espécies de outros lugares do Brasil ou países. A verificação da indicação ou não das espécies quanto ao plantio na calçada e canteiro central foi realizada através de consulta à bibliografia especializada Lorenzi et al. (2003), Prefeitura de São Paulo (2005), Lorenzi (2008), Lorenzi (2009), Lorenzi (2013), Prefeitura de São Paulo (2015) e Vignolia Junior (2016).

Os dados coletados foram inseridos no software Excel 2016 para que alguns parâmetros fossem estimados. Com base no trabalho de Almeida e Neto (2010), a frequência relativa de cada espécie foi calculada com o número de indivíduos encontrados da espécie em questão, dividido pelo total de espécimes e multiplicado por cem para se obter a porcentagem. Em seguida, foi calculado a densidade dos espécimes existentes em dois contextos, de acordo com a localização dos indivíduos, na calçada ou canteiro central. Para tanto, foi dividido o número de indivíduos existente do local, pelo comprimento em $\mathrm{km}$ do canteiro central ou calçada, o resultado foi expresso em árvore $/ \mathrm{km}$.

Para avaliar a biodiversidade encontrada na via em estudo utilizou-se o Índice de Diversidade de Shannon (Fórmula 1). O índice é aplicado para medir diversidade em dados e foi utilizado para medir a biodiversidade de plantas por Silva e Nascimento (2001) e Almeida e Neto (2010). O cálculo é baseado nas espécies encontradas e em sua dominância (número de indivíduos de cada espécie).

$$
H^{\prime}=-\sum_{i=1}^{S} \text { pi. Ln pi }
$$

Onde pi é a divisão entre o número de indivíduos de cada espécie sobre o número total de indivíduos e $L n$ o logaritmo neperiano.

\subsection{Proposta de melhorias da arborização da via}

Após a análise da arborização existente, foi selecionado, aleatoriamente, um trecho da via para realização de uma proposta de melhorias da arborização. Neste contexto, foi feito levantamento topográfico do trecho selecionado, para tanto, utilizou-se receptor GPS de mapeamento Garmin 60CSx e trena com fita de aço Starrett $30 \mathrm{~m}$. Ademais, foram coletados dados de comprimento e largura das pistas, calçadas, canteiro central e estacionamento, além da localização de poste, rede elétrica, iluminação de canteiro central, garagem e árvores. Os dados foram inseridos no software AutoCAD 2017 para confecção de planta.

Persp. Online: exatas \& eng., Campos dos Goytacazes, 24 (09) 34-56 - 2019 seer.perspectivasonline.com.br 
A proposta de melhorias da arborização da via foi baseada em obras como a de Silva e Nascimento (2001), Prefeitura de São Paulo (2005), Carvalho et al. (2006), Lorenzi (2008), Lorenzi (2009), Lorenzi (2013), Prefeitura do Rio de Janeiro (2015) e Prefeitura de São Paulo (2015). Avaliou-se a arborização existente no trecho selecionado, e foi proposto a manutenção de espécies de plantas desejáveis e supressão de espécies indesejáveis. Em seguida, selecionou-se espécies arbóreas nativas do estado do Rio de Janeiro, indicadas à arborização viária e que se adequassem a cada situação onde era possível a implantação da arborização. As espécies remanescentes somadas com as espécies selecionadas para implantação, resultou na composição das espécies da proposta de melhorias da arborização do trecho selecionado.

Em seguida, foi produzido planta da proposta de melhoria da arborização utilizando software AutoCAD 2017. Para avaliar se a proposta de melhorias incrementa a biodiversidade no local, utilizou-se o Índice de Diversidade de Shannon (fórmula 1) para comparar o trecho em estudo.

\section{RESULTADOS E DISCUSSÃO}

Partindo da análise da arborização existente, foi apresentado o quantitativo de espécies encontradas, índices e avaliações quanto a pertinência ou não de espécies na via. Em seguida, foi apresentado a proposta de melhorias da arborização da via, com indicação de espécies para compor a arborização e planta topográfica da área que auxiliou a tomada de decisão para localização e espacialização das árvores selecionadas para plantio.

\subsection{Análise da arborização existente}

Os resultados obtidos para as dimensões da Avenida Senador José Carlos Pereira Pinto foram: 7,0 m em média para largura das duas pistas; calçadas variando de 1,3 m a 5,0 m de largura; estacionamento lateral nas duas pistas com média de $2,5 \mathrm{~m}$ e área permeável no canteiro central variando de $1 \mathrm{~m}$ a 3,7 $\mathrm{m}$. Como não há uniformidade ao longo do percurso da via, foram selecionados quatro pontos e foi feito seções transversais, S1, S2, S3 e S4, para descrever a avenida (Figura 3), a localização dos referidos pontos estão apresentados na figura 1 .

Baseado nos resultados obtidos, as larguras da área permeável do canteiro central permitem o plantio de árvores de pequeno, médio e grande porte, a depender da largura da área permeável e espaço aéreo disponível. Não é recomendado o plantio de árvore em calçada com medidas inferiores a $1,9 \mathrm{~m}$, com o objetivo de manter área livre para acessibilidade (PREFEITURA DE SÃO PAULO, 2015). Porém, há condições de viabilizar, em alguns trechos da avenida, parte do espaço do estacionamento para o plantio de árvores. Para tanto, segundo a Prefeitura Municipal de São Paulo (2015), é necessário, em todos os casos, avaliar a confrontação das árvores a serem plantadas com o mobiliário e equipamentos urbanos.

Persp. Online: exatas \& eng., Campos dos Goytacazes, 24 (09) 34-56 - 2019 seer.perspectivasonline.com.br 


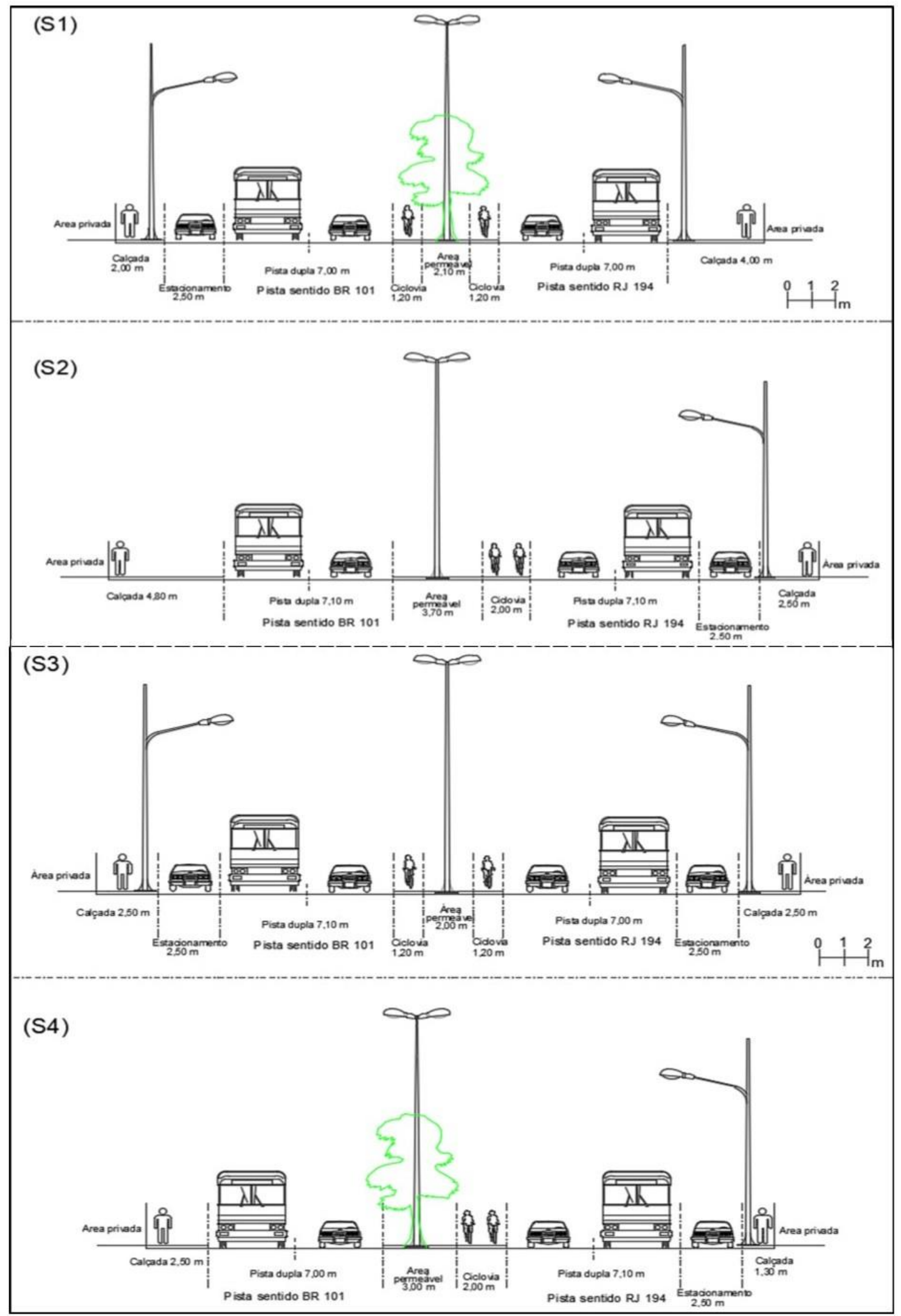

Figura 3: Seções transversais esquemáticas da Av. Senador José Carlos Pereira Pinto nos locais destacados na figura 1.

Persp. Online: exatas \& eng., Campos dos Goytacazes, 24 (09) 34-56 - 2019 seer.perspectivasonline.com.br 
Em relação ao quantitativo das árvores, foram encontrados 245 espécimes, pertencentes a 37 espécies (Tabela 1), sendo 9 nativas, representando 40,4\% dos indivíduos na via e 28 espécies exóticas representando 59,6\% das plantas existente na via. Portanto, com base nos resultados obtidos, confirma-se o que foi publicado por Almeida e Neto (2010), afirmando que no Brasil o plantio de espécies exóticas é comumente realizado na arborização viária urbana. Pode-se afirmar que o número de espécies encontradas na arborização da via pesquisada está baixo, comparado à outras pesquisas como a do município de Cafeara, PA com 51 espécies (LOCASTRO et al., 2017), e Maringá, PA com 87 espécies (BLUM; BORGO; SAMPAIO, 2008).

Tabela 1: Representação quantitativa das espécies encontrada na Av. Senador José Carlos Pereira Pinto, Julho de 2018, nome popular e científico, Total - quantidade total de indivíduos por espécies, FR\% - frequência relativa de indivíduos por espécies, Origem - natiava (espécie com ocorrência no estado do Rio de Janeiro) e exótica (espécie nativa de outras regiões do Brasil ou do mundo)

\begin{tabular}{|c|c|c|c|c|}
\hline Nome popular & Nome científico & Origem & Total & FR (\%) \\
\hline $\begin{array}{l}\text { figueira } \\
\text { benjamina }\end{array}$ & Ficus benjamina $\mathrm{L}$. & Exótica & 20 & 8,16 \\
\hline $\begin{array}{l}\text { ipê-amarelo-de- } \\
\text { jardim }\end{array}$ & Tecoma stans (L.) Juss. ex Kunth & Exótica & 6 & 2,45 \\
\hline flamboyant & Delonix regia (Bojer ex Hook) Raf. & Exótica & 1 & 0,41 \\
\hline leucena & $\begin{array}{l}\text { Leucaena leucocephala (Lam.) R. de } \\
\text { Wit }\end{array}$ & Exótica & 25 & 10,20 \\
\hline oiti & Licania tomentosa (Benth) & Exótica & 4 & 1,67 \\
\hline ipê-roxo & $\begin{array}{l}\text { Handroanthus impetiginosus (Mart. } \\
\text { ex DC.) Mattos }\end{array}$ & Nativa & 10 & 4,08 \\
\hline murta & Murraya paniculata (L.) Jacq. & Exótica & 2 & 0,82 \\
\hline pata-de-vaca-rosa & Bauhinia variegata $\mathrm{L}$. & Exótica & 3 & 1,22 \\
\hline espirradeira & Nerium oleander L. & Exótica & 5 & 2,04 \\
\hline mangueira & Mangifera indica $\mathrm{L}$. & Exótica & 9 & 3,67 \\
\hline cajueiro & Anacardium occidentale L. & Nativa & 9 & 3,67 \\
\hline acerola & Malpighia emarginata DC. & Exótica & 14 & 5,71 \\
\hline resedá & Lagerstroemia indica $\mathrm{L}$. & Exótica & 1 & 0,41 \\
\hline ingá & $\begin{array}{l}\text { Inga vera subsp. Affinis (DC.) T.D. } \\
\text { Penn. }\end{array}$ & Exótica & 1 & 0,41 \\
\hline aroeira salsa & Schinus molle L. & Exótica & 9 & 3,67 \\
\hline
\end{tabular}

Persp. Online: exatas \& eng., Campos dos Goytacazes, 24 (09) 34-56 - 2019 seer.perspectivasonline.com.br 


\begin{tabular}{|c|c|c|c|c|}
\hline aroeira vermelha & Schinus terebinthifolius Raddi & Nativa & 50 & 20,41 \\
\hline pitanga & Eugenia uniflora $\mathrm{L}$. & Nativa & 1 & 0,41 \\
\hline sibipiruna & Caesalpinia pluviosa Benth & Nativa & 15 & 6,12 \\
\hline abio-roxo & Chrysophyllum cainito L. & Exótica & 1 & 0,41 \\
\hline jamelão & Syzygium cumini (L.) Skeels & Exótica & 1 & 0,41 \\
\hline ipê amarelo & $\begin{array}{l}\text { Handroanthus umbellatus (Sond.) } \\
\text { Mattos }\end{array}$ & Nativa & 1 & 0,41 \\
\hline albizia & Albizia falcataria (L.) Fosberg & Exótica & 1 & 0,41 \\
\hline algodão-da-praia & Hibiscus tiliaceus L. & Exótica & 2 & 0,82 \\
\hline cajá- manga & Spolldias cytherea Sonn. Não Tuss. & Exótica & 1 & 0,41 \\
\hline jenipapo & Genipa americana $\mathrm{L}$. & Nativa & 1 & 0,41 \\
\hline graviola & Annona muricata $\mathrm{L}$. & Exótica & 4 & 1,63 \\
\hline pinha & Annona squamosa $\mathrm{L}$. & Exótica & 2 & 0,82 \\
\hline $\begin{array}{l}\text { castanheiro-do- } \\
\text { maranhão }\end{array}$ & Pachira aquatica Aubl. & Exótica & 2 & 0,82 \\
\hline romã & Punica granatum $\mathrm{L}$. & Exótica & 16 & 6,53 \\
\hline palmeira-jerivá & $\begin{array}{l}\text { Syagrus romanzoffiana (Cham.) } \\
\text { Glassman }\end{array}$ & Nativa & 11 & 4,49 \\
\hline pinho-silvestre & Pinus Sylvestris L. & Exótica & 1 & 0,41 \\
\hline seriguela & Spondias purpúrea L. & Exótica & 7 & 2,86 \\
\hline groselha & Phyllanthus acidus (L.) Skeels & Exótica & 2 & 0,82 \\
\hline carambola & Averrhoa carambola $\mathrm{L}$. & Exótica & 2 & 0,82 \\
\hline goiabeira & Psidium guajava $\mathrm{L}$. & Nativa & 1 & 0,41 \\
\hline noni & Morinda citrifolia $\mathrm{L}$. & Exótica & 2 & 0,82 \\
\hline amendoeira & Terminalia catappa $\mathrm{L}$. & Exótica & 2 & 0,82 \\
\hline Total & 37 & & 245 & 100 \\
\hline
\end{tabular}

Realizando a análise do quantitativo de cada espécie, foi verificado a predominância da espécie de pequeno porte Schinus terebinthifolius (aroeira-vermelha) 20,4\% (Figura 4A),

Persp. Online: exatas \& eng., Campos dos Goytacazes, 24 (09) 34-56 - 2019

seer.perspectivasonline.com.br 
nativa e indicada para arborização de rua (LORENZI, 2008). Porém, não é recomendado o plantio de mais de $15 \%$ de indivíduos da mesma espécie. O aumento da diversidade de espécies, minimiza o risco de ocorrência de pragas e doenças, além de outras intempéries que as árvores possam ser submetidas (MILANO, 1984 apud ALMEIDA; NETO, 2010).

Com relação às espécies exóticas, pode-se destacar as seguintes: Leucaena leucocephala (leucena) 10,2\% (Figura 4B), além de ser uma espécie exótica, é considerada invasora e inadequada para arborização urbana (PREFEITURA DE SÃO PAULO, 2015); Ficus benjamina (figueira benjamina) $8,16 \%$ (Figura 4C), é uma espécie que traz preocupação, pois é de origem asiática, resistente, de fácil propagação (VIGNOLIA JUNIOR, 2016) e inconveniente para arborização de calçadas e avenidas, por conta do seu robusto desenvolvimento radicular (LORENZI et al., 2003); Nerium oleander (espirradeira) 2,04\% (Figura 4D), tóxica e inadequada para arborização urbana (PREFEITURA DE SÃO PAULO, 2015). Além disso, espécies exóticas aptas à alimentação humana como a graviola, pinha, manga e seriguela (Figura 4E) foram encontradas, indicando plantio realizado pela população, na maioria das vezes, sem critérios técnicos. No entanto, segundo a Prefeitura Municipal de São Paulo (2015), espécies frutíferas, aptas a alimentação humana, devem ser objeto de projetos específicos na arborização urbana.

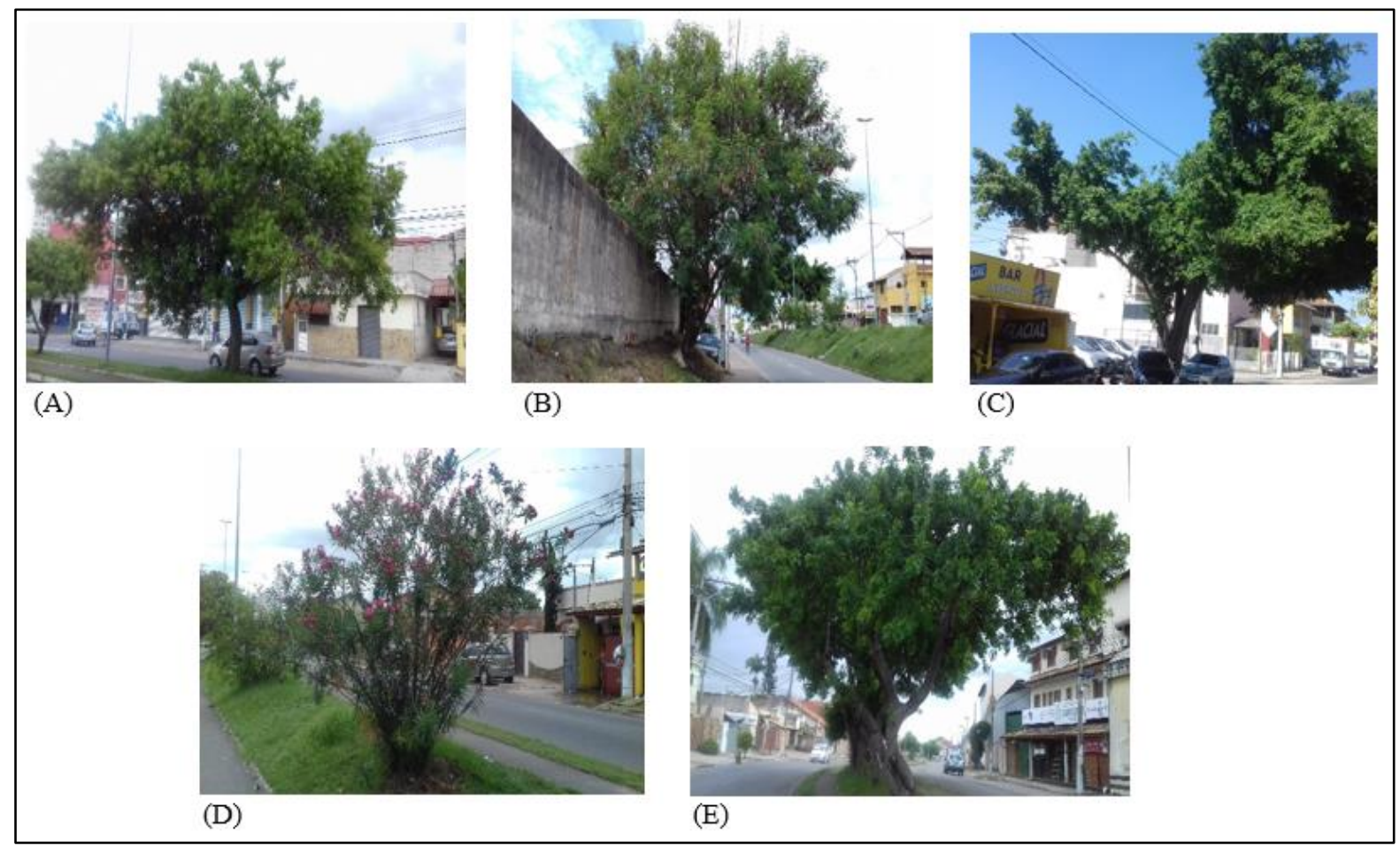

Figura 4: Algumas espécies encontradas na arborização da Av. Senador José Carlos Pereira Pinto. (A) Schinus terebinthifolius (aroeira vermelha) localizada no canteiro central; (B)

Leucaena leucocephala (leucena) localizada em local inapropriado, junto ao muro, e confrontando com rede elétrica; (C) Ficus benjamina (figueira benjamina) confrontando com rede elétrica; (D) Nerium oleander (espirradeira) implantada no canteiro central, onde há circulação de pessoas e (E) Spondias purpúrea (seriguela) localizada no canteiro central.

Em relação às densidades, no canteiro central foram contabilizados 206 indivíduos no trecho de 3,5 km, o que representa uma densidade de 58,8 árvores/km e 39 espécimes contabilizados nas calçadas laterais da avenida, medindo $3,5 \mathrm{~km}$ cada lado, com total de $7 \mathrm{~km}$ de calçada, obtendo-se uma densidade de 5,6 árvores $/ \mathrm{km}$. No entanto, o resultado da pesquisa ficou aquém, comparado com pesquisas anteriores, como as realizadas nas cidades de Colíder

Persp. Online: exatas \& eng., Campos dos Goytacazes, 24 (09) 34-56 - 2019

seer.perspectivasonline.com.br 
e Matupá - MT, onde a densidade de árvores encontradas nas calçadas foram de 71,3 árvores/km e 66,2 árvores/km respectivamente (ALMEIDA; NETO, 2010). Em seguida, foi avaliado a biodiversidade da via aplicando o Índice de Diversidade Shannon, obtendo o valor de 2,87 .

\subsection{Proposta de melhorias na arborização da via}

Esta etapa limitou-se a um trecho de $400 \mathrm{~m}$ da via, selecionada aleatoriamente. Em seguida, foi realizado o diagnóstico da arborização existente no trecho e para sanar os problemas encontrados, foi proposto a implantação de espécies nativas, que se adequassem ao local. As plantas são indicadas para ocupar lugares que não há a presença de arborização e para substituição de espécies indesejáveis. Além disso, selecionou-se espécies que não continham espinhos, não desprendam flores, frutos e folhas com facilidade e que as raízes não danifiquem calçadas e pavimento, reduzindo transtornos e manutenção como limpeza da via e poda de planta. Em suma, busca-se a aceitação, desenvolvimento adequado e a manutenção das árvores na via ao longo do tempo, promovendo o desenvolvimento sustentável da arborização.

\subsubsection{Caracterização e diagnóstico da arborização viária existente em trecho selecionado para proposta de melhorias da arborização}

Foi feito levantamento topográfico e confeccionado planta na escala 1:750 do trecho selecionado, possibilitando a visualização adequada dos detalhes como postes, rede elétrica, calçadas, pista, canteiro central e árvores existentes. As medidas encontradas no trecho foram 2,5 m em média para área permeável do canteiro central, calçadas variando de 1,9 m a 5m, rede aérea de telecomunicações com 5,5 $\mathrm{m}$ de altura média e rede elétrica aérea de baixa e média tensão com $9 \mathrm{~m}$ de altura média. Os resultados encontrados permitem a recomendação da implantação da arborização, sendo necessário a avaliação personalizada para escolha da espécie à situação. A figura $5 \mathrm{~A}$ apresenta a planta da área selecionada para proposta de arborização em local apresentado na figura 1, além disso, localiza a área selecionada para recorte (Figura 5B), que foi apresentada para melhor visualização, e localização de seção transversal apresentada na proposta de melhorias da arborização.

Persp. Online: exatas \& eng., Campos dos Goytacazes, 24 (09) 34-56 - 2019 seer.perspectivasonline.com.br 


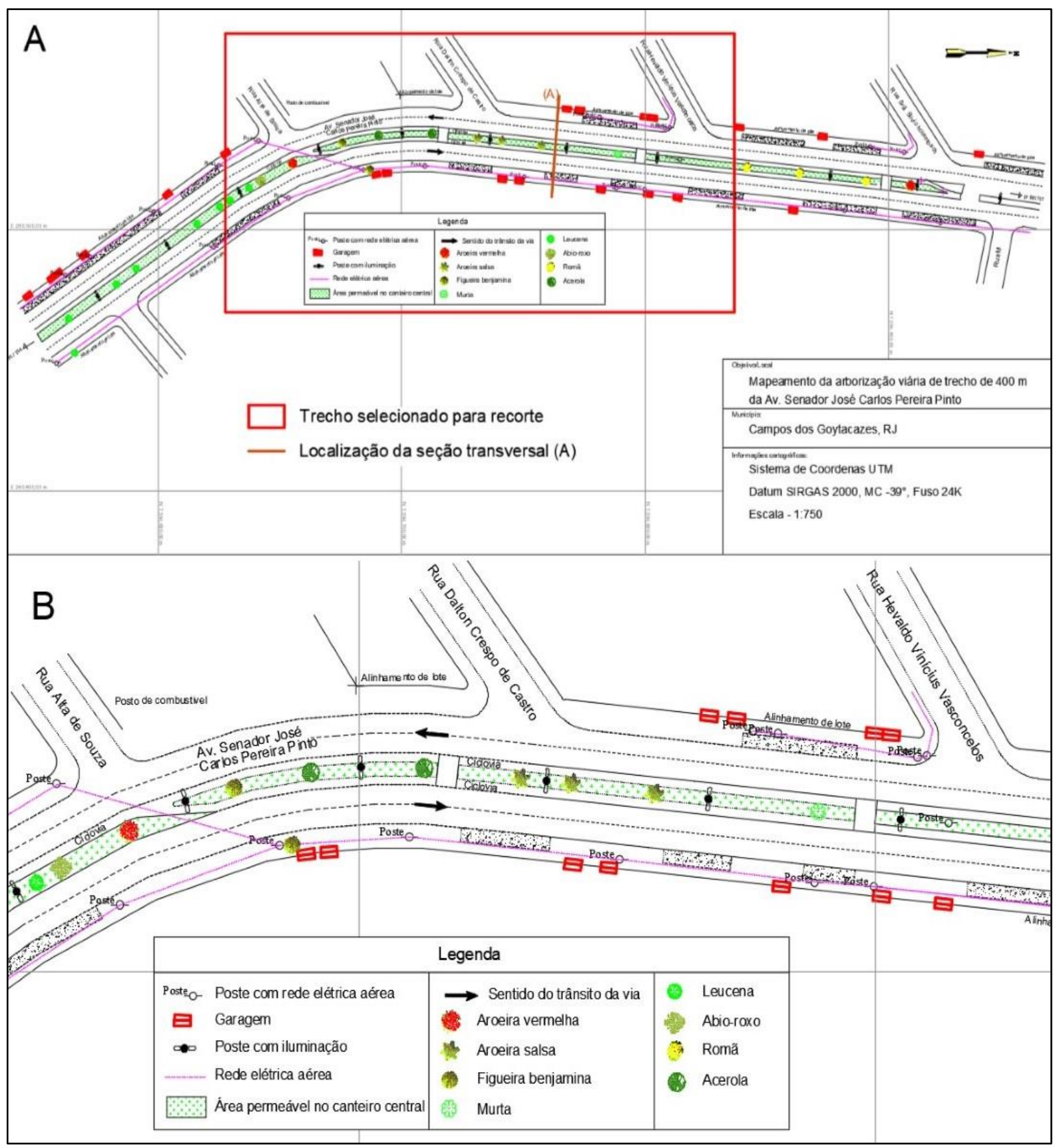

Figura 5: Trechos da avenida Senador José Carlos Pereira Pinto. (A) Planta do trecho selecionado para proposta de melhorias da arborização. (B) Recorte da planta topográfica do trecho selecionado para proposta de arborização.

Vinte plantas de oito espécies distintas foram encontradas no trecho da avenida, entre as espécies encontradas, uma é nativa (10\% do total das plantas) e sete são exóticas (90\% do total de árvores). Portanto, constatou-se que a arborização do trecho selecionado para proposta de melhorias da arborização está ineficiente, com poucas plantas e maioria de espécies exóticas. A tabela 2 apresenta a representação quantitativa das espécies de planta encontradas no trecho do levantamento. 
Tabela 2: Representação quantitativa das espécies de plantas encontradas no trecho selecionado para realização de proposta de melhorias da arborização, nome popular e científico, Local - local encontrado, Qtd. - quantidade encontrada, FR (\%) - frequência relativa no trecho, * espécie nativa do Estado do Rio de Janeiro e ** espécie exóticas

\begin{tabular}{|c|c|c|c|c|}
\hline Nome popular & Nome científico & Local & Qtd. & $\begin{array}{l}\text { FR } \\
(\%)\end{array}$ \\
\hline aroeira vermelha* & $\begin{array}{l}\text { Schinus terebinthifolius } \\
\text { Raddi }\end{array}$ & canteiro central & 2 & 10 \\
\hline aroeira salsa** & Schinus molle L. & canteiro central & 3 & 15 \\
\hline $\begin{array}{l}\text { figueira } \\
\text { benjamina** }\end{array}$ & Ficus benjamina L. & $\begin{array}{c}\text { canteiro central e sob } \\
\text { rede elétrica }\end{array}$ & 2 & 10 \\
\hline murta** & $\begin{array}{l}\text { Murraya paniculata } \\
\text { (L.) Jacq. }\end{array}$ & canteiro central & 1 & 5 \\
\hline leucena** & $\begin{array}{l}\text { Leucaena leucocephala } \\
\text { (Lam.) R. de Wit }\end{array}$ & $\begin{array}{l}\text { canteiro central e sob } \\
\text { rede elétrica }\end{array}$ & 5 & 25 \\
\hline abio-roxo** & $\begin{array}{l}\text { Chrysophyllum cainito } \\
\text { L. }\end{array}$ & canteiro central & 1 & 5 \\
\hline acerola** & $\begin{array}{l}\text { Malpighia emarginata } \\
\text { DC. }\end{array}$ & canteiro central & 3 & 15 \\
\hline romã $\tilde{a}^{*}$ & Punica granatum $\mathrm{L}$. & canteiro central & 3 & 15 \\
\hline Total & 8 & & 20 & 100 \\
\hline
\end{tabular}

Em seguida, foi feito avaliação das espécies encontradas e para a proposta de arborização, foi indicado a manutenção de espécies desejáveis e supressão das espécies indesejáveis. Neste contexto, a aroeira vermelha, Schinus terebinthifolia (Figura 6A), é uma espécie nativa de pequeno porte recomendada para arborização de ruas (LORENZI, 2008). Portanto, as duas plantas encontradas no canteiro central da via foram preservadas na proposta de melhorias da arborização.

Segundo a obra da Prefeitura de São Paulo (2015), deve-se dar preferência ao plantio de espécie nativas na arborização de ruas, porém, é possível o uso de espécies exóticas recomendadas e adequadas ao local de implantação. Na proposta de melhorias deste artigo foram mantidas duas espécies exóticas: a murta e a aroeira salsa. A murta, Murraya paniculata (Figura 6B) é uma árvore ornamental de pequeno porte de origem asiática (LORENZI et. al., 2003) e a aroeira salsa, Schinus molle, de pequeno porte, com registro de ocorrência no estado de Minas Gerais e nos estados do Sul do país (LORENZI, 2008). A decisão de manter estas plantas deve-se ao fato de serem recomendadas na arborização de ruas e por estrarem implantadas sem causar confrontação com o mobiliário e equipamentos urbanos. No entanto, não será acrescentado novas plantas dessas espécies na proposta.

Persp. Online: exatas \& eng., Campos dos Goytacazes, 24 (09) 34-56 - 2019 seer.perspectivasonline.com.br 
Foi sugerido a eliminação das outras espécies exóticas encontradas no trecho da via, entre elas: figueira benjamina, leucina, romã, acerola e abio-roxo. Duas figueiras benjamina, Ficus benjamina (Figura 6C), espécie de origem asiática de grande porte e inconveniente para arborização de ruas e avenidas devido seu robusto sistema radicular (LORENZI et. al., 2003), estão localizadas no canteiro central e sob a rede elétrica. Por estes motivos de confrontação recomenda-se a retirada. A leucena, Leucaena leucocephala, é considerada invasora e inapropriada para arborização urbana (PREFEITURA DE SÃO PAULO, 2015). Portanto, as cinco plantas encontradas na via foram suprimidas da proposta de melhorias da arborização. As espécies Punica granatum (romã) (Figura 6D), Malpighia emarginata (acerola) (Figura 6E) e Chrysophyllum cainito (abio-roxo), são espécies exóticas aptas à alimentação humana. Segundo Prefeitura de São Paulo (2015), espécies aptas à alimentação humana devem fazer parte de projetos específico. Portanto, as sete plantas das espécies mencionadas anteriormente foram suprimidas da proposta de melhorias da arborização da via.

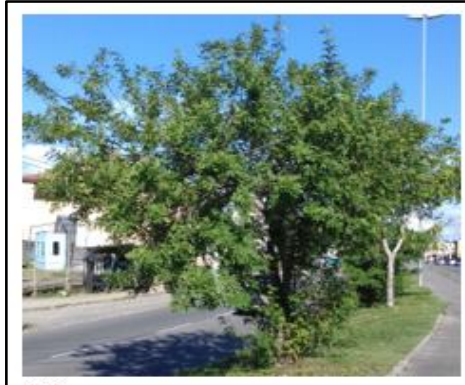

(A)

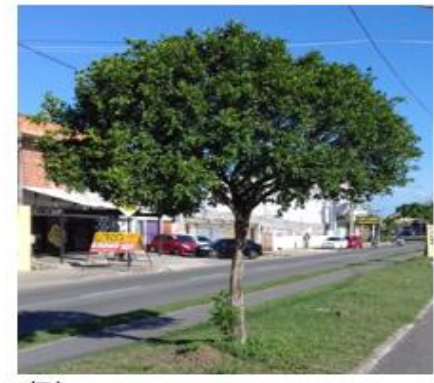

(B)

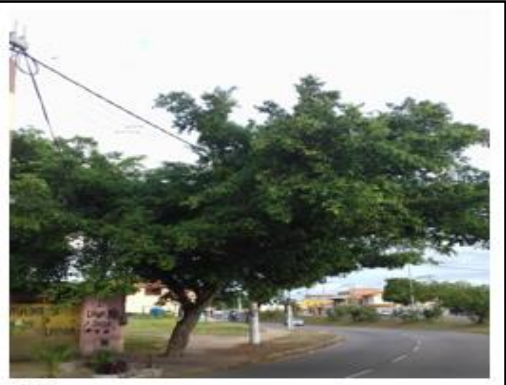

(C)

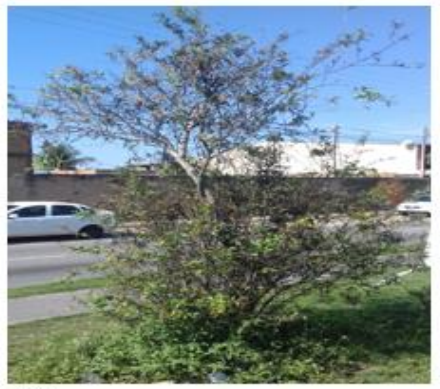

(D)

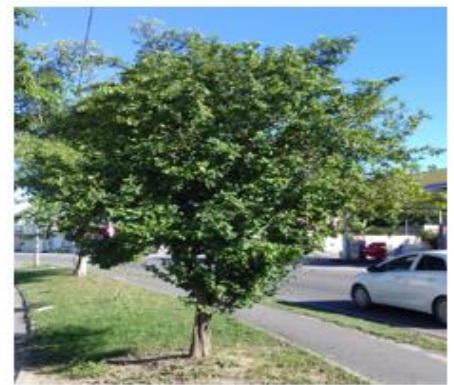

(E)

Figura 6: Algumas espécies encontradas no trecho selecionado para proposta de melhorias da arborização da Av. Senador José Carlos Pereira Pinto. (A) Schinus terebinthifolius (aroeira vermelha) localizada no canteiro central; (B) Murraya paniculata (murta) localizada no canteiro central; (C) Ficus benjamina (figueira benjamina) localizada na calçada e confrontando com rede elétrica; (D) Punica granatum L. (romã) localizada no canteiro central; (E) Malpighia emarginata (acerola) localizada no canteiro central.

\subsubsection{Composição das espécies de plantas da proposta de melhorias da arborização}

Persp. Online: exatas \& eng., Campos dos Goytacazes, 24 (09) 34-56 - 2019

seer.perspectivasonline.com.br 
Foram selecionadas 24 espécies de plantas para serem introduzidas na arborização da via, além de serem indicadas para arborização de rua são nativas do estado do Rio de Janeiro. Entre as espécies selecionadas, 13 são de pequeno porte, com altura variável entre 3 a 8 metros, 8 espécies de médio porte, com variação de altura entre 4 a 16 metros e 3 espécies de grande porte podendo atingir medidas entre 10 a 20 metros de altura. A tabela 3 apresenta as espécies selecionadas e a bibliografia que confirma a indicação da espécie para arborização de ruas e ocorrência no estado do Rio de Janeiro.

Tabela 3: Seleção de espécies de plantas para serem introduzidas na proposta de melhorias da arborização da via, nome popular e científico, bibliografia que indica a espécie para plantio em vias, bibliografia que cita a ocorrência da espécie no Estado do Rio de Janeiro e \# espécies com registro de ocorrência em floresta de baixada aluvial ou de tabuleiro da região

\begin{tabular}{|c|c|c|c|}
\hline Nome popular & Nome científico & $\begin{array}{c}\text { Bibliografia que } \\
\text { indica a espécie para } \\
\text { plantio em ruas }\end{array}$ & $\begin{array}{l}\text { Bibliografia que cita a } \\
\text { ocorrência da espécie no } \\
\text { Estado do Rio de Janeiro }\end{array}$ \\
\hline unha-de-vaca & $\begin{array}{l}\text { Bauhinia longifolia } \\
\text { (Bong.) Steud. }\end{array}$ & $\begin{array}{l}\text { Prefeitura de São } \\
\text { Paulo (2015) }\end{array}$ & $\begin{array}{l}\text { Prefeitura do Rio de } \\
\text { Janeiro (2015) }\end{array}$ \\
\hline guaçatonga \# & $\begin{array}{l}\text { Casearia sylvestris } \\
\text { SW. }\end{array}$ & $\begin{array}{l}\text { Lorenzi }(2008) \text { e } \\
\text { Prefeitura de São } \\
\text { Paulo (2015) }\end{array}$ & $\begin{array}{c}\text { Silva e Nascimento } \\
\text { (2001), Carvalho } \text { et. al } \\
\text { (2006) e Lorenzi (2008) }\end{array}$ \\
\hline $\begin{array}{l}\text { guamirim-de- } \\
\text { folha-fina }\end{array}$ & $\begin{array}{l}\text { Myrcia splendens } \\
\text { (SW.) DC }\end{array}$ & $\begin{array}{l}\text { Lorenzi }(2013) \text { e } \\
\text { Prefeitura de São } \\
\text { Paulo (2015) }\end{array}$ & $\begin{array}{c}\text { Lorenzi (2013) e Prefeitura } \\
\text { do Rio de Janeiro (2015) }\end{array}$ \\
\hline araçá & $\begin{array}{l}\text { Psidium } \\
\text { cattleianum Sabine }\end{array}$ & $\begin{array}{l}\text { Lorenzi }(2008) \text { e } \\
\text { Prefeitura de São } \\
\text { Paulo (2015) }\end{array}$ & $\begin{array}{c}\text { Lorenzi (2008) e Prefeitura } \\
\text { do Rio de Janeiro (2015) }\end{array}$ \\
\hline tingui-preto & $\begin{array}{l}\text { Dictyoloma } \\
\text { vandellianum A. } \\
\text { Juss. }\end{array}$ & $\begin{array}{l}\text { Lorenzi }(2008) \text { e } \\
\text { Prefeitura de São } \\
\text { Paulo (2015) }\end{array}$ & $\begin{array}{c}\text { Lorenzi (2008) e Prefeitura } \\
\text { do Rio de Janeiro (2015) }\end{array}$ \\
\hline carobinha & $\begin{array}{l}\text { Jacaranda } \\
\text { puberula Cham. }\end{array}$ & $\begin{array}{l}\text { Lorenzi }(2008) \text { e } \\
\text { Prefeitura de São } \\
\text { Paulo (2015) }\end{array}$ & Lorenzi (2008) \\
\hline cataia & $\begin{array}{l}\text { Drimys brasiliensis } \\
\text { Miers }\end{array}$ & Lorenzi (2008) & Lorenzi (2008) \\
\hline guaxupita & $\begin{array}{l}\text { Esenbeckia } \\
\text { grandiflora Mart. }\end{array}$ & Lorenzi (2008) & $\begin{array}{c}\text { Lorenzi (2008) e Prefeitura } \\
\text { do Rio de Janeiro (2015) }\end{array}$ \\
\hline $\begin{array}{l}\text { baga-de- } \\
\text { morcego }\end{array}$ & $\begin{array}{l}\text { Trichilia pallens } C \text {. } \\
D C .\end{array}$ & Lorenzi (2009) & Lorenzi (2009) \\
\hline camboim & $\begin{array}{l}\text { Myrciaria } \\
\text { cuspidata } \text { O. Berg }\end{array}$ & Lorenzi (2009) & Lorenzi (2009) \\
\hline
\end{tabular}

Persp. Online: exatas \& eng., Campos dos Goytacazes, 24 (09) 34-56 - 2019 seer.perspectivasonline.com.br 


\begin{tabular}{|c|c|c|c|}
\hline timbó-mirim & $\begin{array}{l}\text { Allophylus } \\
\text { petiolulatus Radik }\end{array}$ & Lorenzi (2009) & Lorenzi (2009) \\
\hline guamixinga & $\begin{array}{l}\text { Galipea } \\
\text { jasminiflora (A. } \\
\text { St.-Hil.) Engl. }\end{array}$ & Lorenzi (2009) & $\begin{array}{c}\text { Lorenzi (2008) e Prefeitura } \\
\text { do Rio de Janeiro (2015) }\end{array}$ \\
\hline estífia-branca & $\begin{array}{l}\text { Stifftia parviflora } \\
\text { (Leandro) D. Don }\end{array}$ & Lorenzi (2009) & Lorenzi (2009) \\
\hline babosa branca & $\begin{array}{l}\text { Cordia superba } \\
\text { Cham. }\end{array}$ & $\begin{array}{l}\text { Lorenzi }(2008) \text { e } \\
\text { Prefeitura de São } \\
\text { Paulo (2015) }\end{array}$ & $\begin{array}{c}\text { Lorenzi (2008) e Prefeitura } \\
\text { do Rio de Janeiro (2015) }\end{array}$ \\
\hline quaresmeira & $\begin{array}{l}\text { Tibouchina } \\
\text { granulosa (Desr.) } \\
\text { Cogn. }\end{array}$ & $\begin{array}{l}\text { Lorenzi }(2008) \text { e } \\
\text { Prefeitura de São } \\
\text { Paulo (2015) }\end{array}$ & $\begin{array}{c}\text { Lorenzi (2008) e Prefeitura } \\
\text { do Rio de Janeiro (2015) }\end{array}$ \\
\hline ipê-branco \# & $\begin{array}{l}\text { Tabebuia } \\
\text { roseoalba (Ridl.) } \\
\text { Sandwith }\end{array}$ & $\begin{array}{l}\text { Lorenzi (2008) e } \\
\text { Prefeitura de São } \\
\text { Paulo (2015) }\end{array}$ & $\begin{array}{l}\text { Silva e Nascimento (2001) } \\
\text { e Prefeitura do Rio de } \\
\text { Janeiro (2015) }\end{array}$ \\
\hline ipê-verde \# & $\begin{array}{l}\text { Cybistax } \\
\text { antisyphilitica } \\
\text { (Mart.) Mart. }\end{array}$ & $\begin{array}{l}\text { Lorenzi (2008) e } \\
\text { Prefeitura de São } \\
\text { Paulo (2015) }\end{array}$ & $\begin{array}{l}\text { Carvalho et. al (2006) e } \\
\text { Prefeitura do Rio de } \\
\text { Janeiro (2015) }\end{array}$ \\
\hline ipê-amarelo & $\begin{array}{l}\text { Handroanthus } \\
\text { chrysotrichus } \\
\text { (Mart. ex DC.) } \\
\text { Mattos }\end{array}$ & $\begin{array}{l}\text { Lorenzi (2008) e } \\
\text { Prefeitura de São } \\
\text { Paulo (2015) }\end{array}$ & $\begin{array}{c}\text { Lorenzi (2008) e Prefeitura } \\
\text { do Rio de Janeiro (2015) }\end{array}$ \\
\hline aldrago & $\begin{array}{l}\text { Pterocarpus } \\
\text { violaceus Vogel }\end{array}$ & $\begin{array}{l}\text { Lorenzi }(2008) \text { e } \\
\text { Prefeitura de São } \\
\text { Paulo (2015) }\end{array}$ & $\begin{array}{l}\text { Prefeitura do Rio de } \\
\quad \text { Janeiro (2015) }\end{array}$ \\
\hline açoita-cavalo & $\begin{array}{l}\text { Luehea candicans } \\
\text { Mart. }\end{array}$ & $\begin{array}{l}\text { Lorenzi (2008) e } \\
\text { Prefeitura de São } \\
\text { Paulo (2015) }\end{array}$ & Lorenzi (2008) \\
\hline $\begin{array}{l}\text { sabão de } \\
\text { soldado \# }\end{array}$ & $\begin{array}{l}\text { Sapindus } \\
\text { saponária } \mathrm{L} .\end{array}$ & $\begin{array}{l}\text { Lorenzi }(2008) \text { e } \\
\text { Prefeitura de São } \\
\text { Paulo (2015) }\end{array}$ & $\begin{array}{l}\text { Carvalho et. al (2006), } \\
\text { Lorenzi (2008) e Prefeitura } \\
\text { do Rio de Janeiro (2015) }\end{array}$ \\
\hline ipê-roxo & $\begin{array}{l}\text { Handroanthus } \\
\text { heptaphyllus (vell.) } \\
\text { Mattos }\end{array}$ & $\begin{array}{l}\text { Lorenzi (2008) e } \\
\text { Prefeitura de São } \\
\text { Paulo (2015) }\end{array}$ & $\begin{array}{c}\text { Lorenzi (2008) e Prefeitura } \\
\text { do Rio de Janeiro (2015) }\end{array}$ \\
\hline sapuva & $\begin{array}{l}\text { Machaerium } \\
\text { stipitatum (DC.) } \\
\text { Vogel }\end{array}$ & $\begin{array}{l}\text { Lorenzi (2008) e } \\
\text { Prefeitura de São } \\
\text { Paulo (2015) }\end{array}$ & $\begin{array}{l}\text { Lorenzi (2008) e Prefeitura } \\
\text { do Rio de Janeiro (2015) }\end{array}$ \\
\hline
\end{tabular}

Persp. Online: exatas \& eng., Campos dos Goytacazes, 24 (09) 34-56 - 2019 seer.perspectivasonline.com.br 
Após a seleção de espécies a serem mantidas na via e escolha das espécies a serem implantadas, foi possível compor a lista de plantas a serem propostas para o trecho em estudo (Tabela 4). A sugestão de plantio foi basicamente para atender a três situações de localização distintas: área permeável do canteiro central, sob rede elétrica ou de telecomunicação e calçada com espaço aéreo livre. Ademais, foi priorizado espécies de médio e grande porte, com quantitativo equilibrado e alternância na distribuição das espécies, evitando concentração ou predominância. $\mathrm{O}$ espaçamento de implantação entre as plantas de pequeno, médio e grande porte proposto foi de no mínimo, $5 \mathrm{~m}, 8 \mathrm{~m}, 12 \mathrm{~m}$ respectivamente, em caso de mudança de porte, utilizou-se o mínimo a média entre os espaçamentos dos portes (PREFEITURA DE SÃO PAULO, 2015).

Tabela 4: Representação quantitativa das espécies que compõem a proposta de melhorias da arborização da Av. Senador José Carlos Pereira Pinto (trecho selecionado), nome popular, Alt. (m) - limites de altura das espécies em metros, Porte - (P) pequeno, (M) médio e $(\mathrm{G})$ grande, local de implantação, FR\% - frequência relativa de indivíduos por espécies, * espécies nativas do Estado do Rio de janeiro e ${ }^{* *}$ espécies exótica remanescentes preservadas na proposta

\begin{tabular}{lcccccc}
\hline Nome popular & Alt. (m) & Porte & Local de implantação & Qtd. & FR (\%) \\
\hline unha-de-vaca* & $4-7$ & $\mathrm{P}$ & sob rede elétrica & 6 & 5,3 \\
guaçatonga* & $4-6$ & $\mathrm{P}$ & sob rede elétrica & 6 & 5,3 \\
$\begin{array}{l}\text { guamirim-de-folha-fina* } \\
\text { araçá* }\end{array}$ & $4-8$ & $\mathrm{P}$ & sob rede elétrica & 6 & 5,3 \\
$\begin{array}{l}\text { tingui-preto* } \\
\text { carobinha* }\end{array}$ & $3-6$ & $\mathrm{P}$ & sob rede elétrica & 6 & 5,3 \\
cataia* & $4-7$ & $\mathrm{P}$ & sob rede elétrica & 6 & 5,3 \\
guaxupita* & $4-7$ & $\mathrm{P}$ & sob rede elétrica & 6 & 5,3 \\
$\begin{array}{l}\text { baga-de-morcego* } \\
\text { camboim* }\end{array}$ & $4-8$ & $\mathrm{P}$ & sob rede elétrica & 5 & 4,4 \\
timbó-mirim* & $4-7$ & $\mathrm{P}$ & sob rede elétrica & 5 & 4,4 \\
guamixinga* & $3-6$ & $\mathrm{P}$ & sob rede elétrica & 5 & 4,4 \\
& $4-6$ & $\mathrm{P}$ & sob rede elétrica & 5 & 4,4 \\
& $4-6$ & $\mathrm{P}$ & sob rede elétrica & 5 & 4,4
\end{tabular}

Persp. Online: exatas \& eng., Campos dos Goytacazes, 24 (09) 34-56 - 2019 seer.perspectivasonline.com.br 


\begin{tabular}{lccccc} 
estífia-branca* & $4-8$ & $\mathrm{P}$ & sob rede elétrica & 5 & 4,4 \\
babosa branca* & $7-10$ & $\mathrm{M}$ & calçada/canteiro central & 4 & 3,5 \\
$\begin{array}{l}\text { quaresmeira* } \\
\text { ipê-branco* }\end{array}$ & $8-12$ & $\mathrm{M}$ & canteiro central & 3 & 2,6 \\
ipê-verde* & $7-12$ & $\mathrm{M}$ & calçada/canteiro central & 4 & 3,5 \\
$\begin{array}{l}\text { ipê-amarelo* } \\
\text { aldrago* }\end{array}$ & $6-12$ & $\mathrm{M}$ & canteiro central & 3 & 2,6 \\
açoita-cavalo* & $4-10$ & $\mathrm{M}$ & calçada/canteiro central & 4 & 3,5 \\
sabão de soldado * & $8-14$ & $\mathrm{M}$ & canteiro central & 3 & 2,6 \\
ipê-roxo* & $8-12$ & $\mathrm{M}$ & calçada/canteiro central & 4 & 3,5 \\
sapuva* & $5-9$ & $\mathrm{M}$ & canteiro central & 3 & 2,6 \\
grumixama* & $10-20$ & $\mathrm{G}$ & canteiro central & 3 & 2,6 \\
aroeira vermelha* & $10-20$ & $\mathrm{G}$ & canteiro central & 3 & 2,6 \\
aroeira salsa** & $10-15$ & $\mathrm{G}$ & canteiro central & 3 & 2,6 \\
murta** & $5-8$ & $\mathrm{P}$ & canteiro central & 2 & 1,7 \\
\hline Total & $5-8$ & $\mathrm{P}$ & canteiro central & 3 & 2,6 \\
\hline & $5-7$ & $\mathrm{P}$ & canteiro central & 1 & 0,9 \\
\hline
\end{tabular}

Para o plantio sob rede elétrica indicou-se árvores de pequeno porte como a Psidium cattleianum (araçá) (Figura 7A), Myrcia splendens (guamirim-de-folha-fina) (Figura 7B) e Casearia sylvestris (guaçatonga) (Figura 7C), além de possuírem raízes que não danificam calçadas (PREFEITURA DE SÃO PAULO, 2015), são ornamentais, produzem alimento para fauna e são indicadas para plantio em ruas sob rede elétrica (LORENZI, 2008). Ademais, as árvores foram distribuídas de maneira a evitar obstrução de garagens e confrontação com postes. As espécies de pequeno porte representaram 67,8\% dos indivíduos propostos.

Espécies de médio porte como a Tabebuia roseoalba (ipê-branco) (Figura 7D) e Handroanthus chrysotrichus (ipê-amarelo) (Figura 7E), foram indicadas para plantio na calçada à margem da via. Além de serem plantas ornamentais, possuem a arquitetura da copa elíptica vertical (PREFEITURA DE SÃO PAULO, 2015), evitando que galhos possam obstruir a parte aérea da pista e minimizando podas, considerando que veículos de grande porte transitam a via. Para a área permeável do canteiro central, indicou-se implantação de espécies de médio e grande porte. As árvores foram distribuídas obedecendo aos critérios descrito no trabalho e evitando conflitos com a iluminação presente no canteiro central. As plantas de médio e grande porte representam $24,4 \%$ e $7,8 \%$ respectivamente, da configuração total de árvores indicada no trabalho.

Persp. Online: exatas \& eng., Campos dos Goytacazes, 24 (09) 34-56 - 2019 seer.perspectivasonline.com.br 


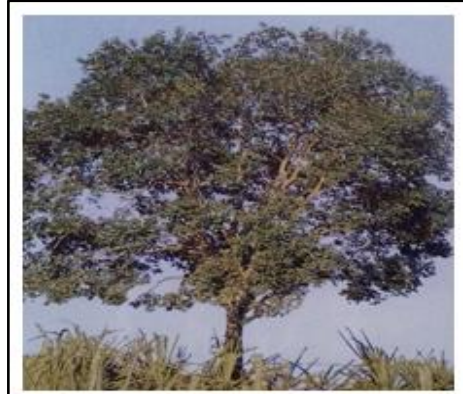

(A)

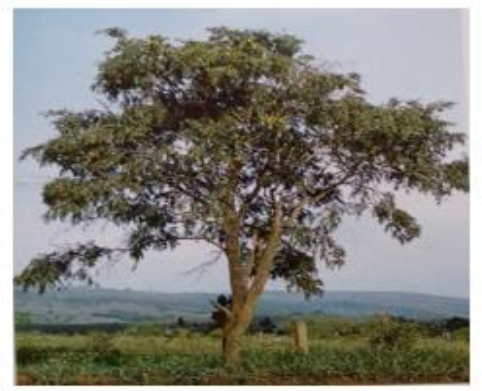

(B)

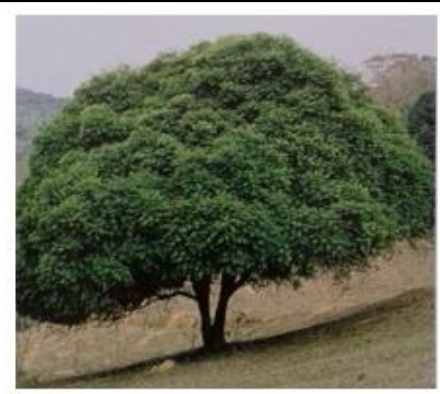

(C)

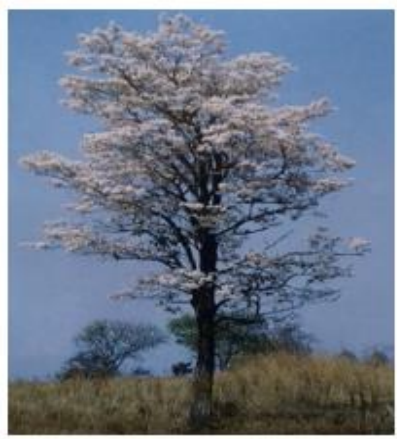

(D)

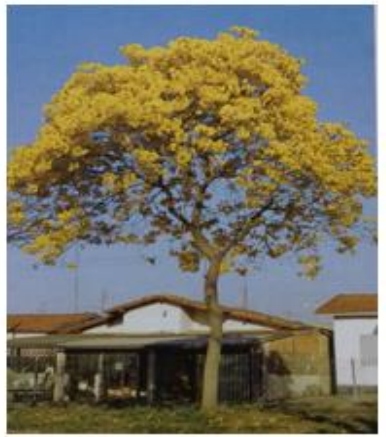

(E)

Figura 7: Algumas espécies selecionadas para proposta de melhorias da arborização da Av. Senador José Carlos Pereira Pinto. (A) Psidium cattleianum (araçá); (B) Myrcia splendens (guamirim-de-folha-fina); (C) Casearia sylvestris (guaçatonga); (D) Tabebuia roseoalba (ipêbranco); (E) Handroanthus chrysotrichus (ipê-amarelo). (Fonte: Lorenzi, 2008).

Utilizando a planta produzida no levantamento topográfico da área estudada, foi possível projetar a especialização das árvores a serem plantadas e suprimir as plantas indesejáveis ou inapropriadas que se encontram na via. Neste contexto, foi produzido a planta da proposta de melhorias da arborização. A figura 8 apresenta um recorte da planta mencionada anteriormente em local indicado na figura 5A.

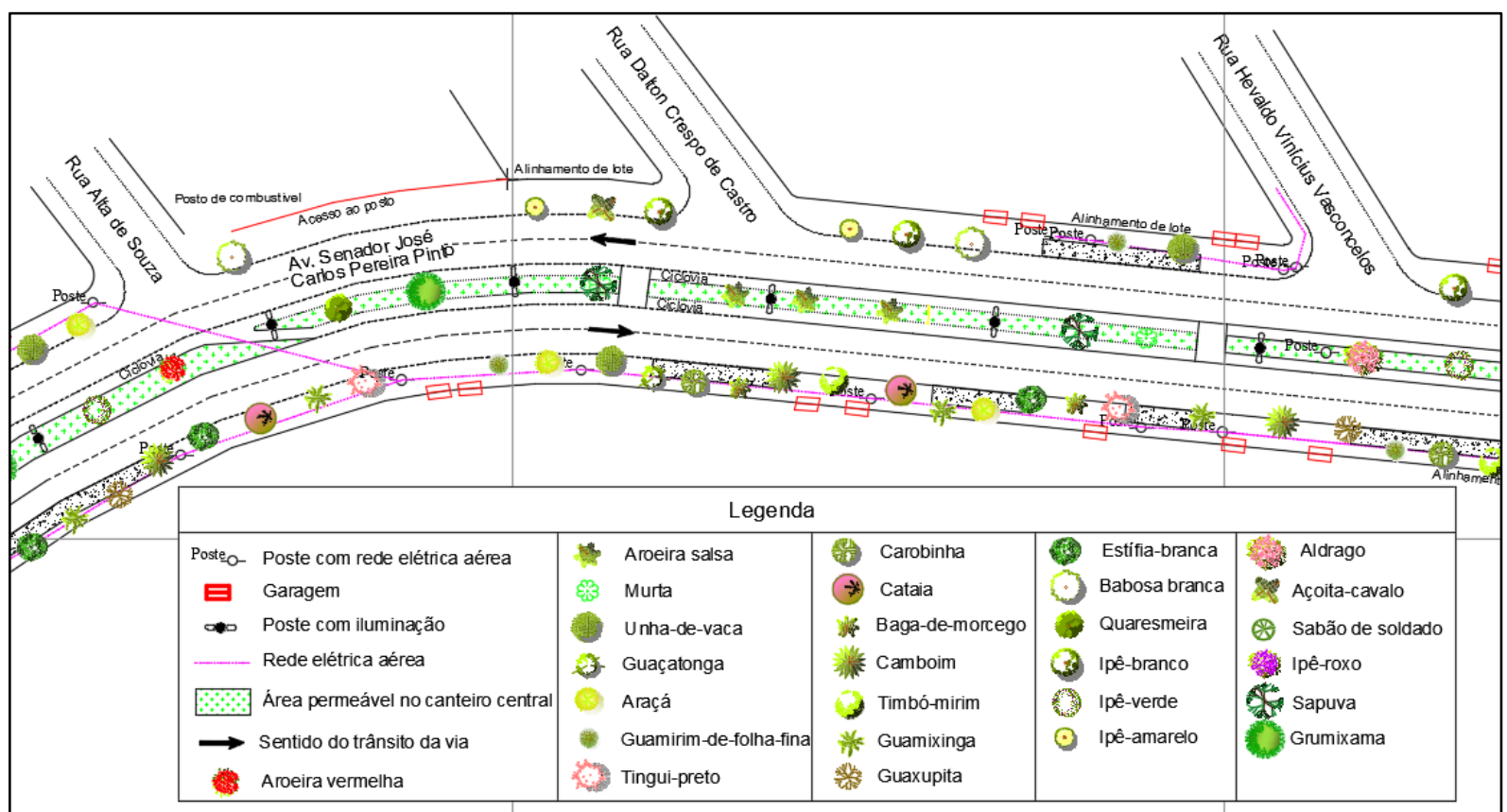

Persp. Online: exatas \& eng., Campos dos Goytacazes, 24 (09) 34-56 - 2019

seer.perspectivasonline.com.br 
Figura 8: Recorte de trecho da planta da proposta de melhorias na arborização da Av. Senador José Carlos Pereira Pinto no trecho localizado na figura 5A.

A figura 9, apresenta seção transversal do cadastro (Figura 9A) e proposta (Figura 9B) em local indicado na figura 5A. Realizando a comparação visual entre as seções, é possível visualizar o enriquecimento da arborização, com espécies de maior porte na área permeável do canteiro central e presença de espécies adequadas nas calçadas.

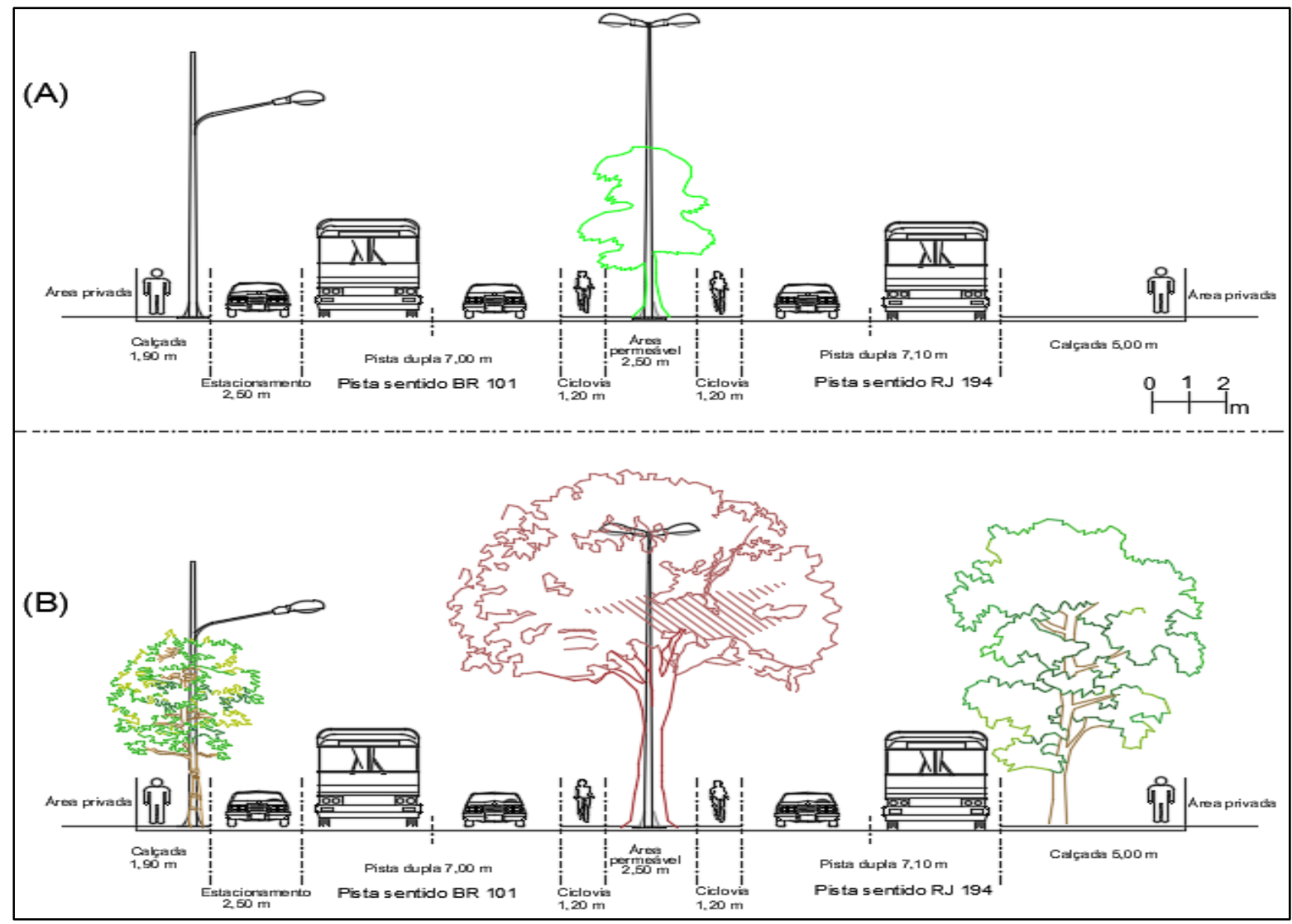

Figura 9: Seções transversais esquemáticas (cadastro "A" e proposta "B") da Av. Senador José Carlos Pereira Pinto no local indicado na figura 5A.

A proposta prevê a implantação de 108 plantas e a supressão de 14 árvores, entre estas estão espécies não apropriadas para arborização urbana como a leucena, indesejáveis na via como romã e acerola e presentes em locais indesejáveis como figueira benjamina, sob rede elétrica, calçada e canteiro central. Além disso, manutenção de 6 árvores de espécies desejáveis como a aroeira vermelha e a aroeira salsa. Em suma, foram encontradas 20 árvores no trecho da via e a proposta prevê aumento para 114 árvores no mesmo trecho de 400 metros.

Fazendo uma análise visual entre os dois recortes de plantas apresentados na pesquisa (Figura 5B e 8), é notório a escassez de árvores na planta primitiva (Figura 5B), em contrapartida, a planta gerada na proposta (Figura 8) apresenta abundância de árvores. Além disso, a biodiversidade no trecho de $400 \mathrm{~m}$ analisado de forma específica é de 1,96, porém, se a proposta de melhoria fosse implementada o índice passaria para 3,23. Os resultados da avaliação da biodiversidade foram obtidos através da aplicação da fórmula 1 (Índice de Diversidade de Shannon). 


\section{CONCLUSÕES}

A arborização viária da área estudada encontra-se ineficiente, com baixa densidade arbórea, predominância da espécie nativa Schinus terebinthifolius (aroeira vermelha) e espécies exóticas inapropriadas para arborização urbana como a Leucaena leucocephala (leucena) e Nerium oleander (espirradeira). Para sanar os problemas encontrados, propõe-se a implantação de espécies de pequeno porte sob rede elétrica, médio porte para calçadas e de pequeno a grande porte para o canteiro central. Com isso, conclui-se que a proposta apresentada revitalizará a arborização local e melhorará o indicador de biodiversidade.

Foi constatado a necessidade da prefeitura municipal realizar planejamento da arborização do município de Campos dos Goytacazes. Pois não há um dispositivo legal, plano diretor municipal de arborização, mesmo sendo previsto sua elaboração no plano diretor municipal, que foi criado no ano de 2008. Como resultado, as árvores acabam sendo plantadas sem critérios técnicos, não atingindo aos objetivos esperados.

Em suma, o trabalho trouxe à luz informações e opção de resolução de problemas na arborização da via estudada. Além disso, a pesquisa apresenta dados que comprovam a necessidade de se trabalhar melhor a arborização no município. Ademais, os resultados apresentados podem auxiliar na tomada de decisão para o desenvolvimento da arborização viária, minimizando os impactos da urbanização, reduzindo custos e proporcionando equilíbrio ambiental.

\section{REFERÊNCIAS}

ALMEIDA, D. N. de; NETO, R. M. R. Análise da arborização urbana de duas cidades da região norte do estado de Mato Grosso. Revista Árvore, v. 34, n. 5, p. 899-906, out. 2010.

ASSOCIAÇÃO BRASILEIRA DE NORMAS TÉCNICAS (ABNT). NBR 9050 Acessibilidade a edificações, mobiliário, espaços e equipamentos urbanos. Rio de Janeiro, 2015.

ÁVILA, M. R.; PANCHER, A. M. Estudos das áreas verdes urbanas como indicador de qualidade ambiental no município de americana - SP. Revista Brasileira de Cartografia, Rio de Janeiro, n. 67/3, p. 527-544, maio/jun. 2015.

AZA, N. M. F. Análise da distribuição espacial da cobertura arbórea urbana através da relação das variáveis socioeconômicas, Ipatinga - MG. 2016. 85 f. Dissertação de mestrado. Programa de pós-graduação em ciência florestal, Universidade Federal de Viçosa MG, 2016. Disponível em: <http://bdtd.ibict.br/vufind/>. Acesso em: 19 nov. 2017.

BARGOS, D. C.; MATIAS, L. F. Mapeamento e análise de áreas verdes urbanas em Paulínia (SP): estudo com a aplicação de geotecnologias. Soc. \& Nat., Uberlândia, ano 24, n. 1, p. 143-156, jan./abr. 2012.

BLUM, C. T.; BORGO, M.; SAMPAIO, A. C. F. Espécies exóticas invasoras na arborização de vias públicas de Maringá-PR. Rev. SBAU, Piracicaba, v. 3, n. 2, p. 78-97, jun. 2008.

CARVAlHO, F. A. et al. Comunidade arbórea de uma floresta de baixada aluvial no município de Campos dos Goytacazes, RJ. Cerne, Lavras, v. 12, n. 2, p. 157-166, abr./jun. 2006

Persp. Online: exatas \& eng., Campos dos Goytacazes, 24 (09) 34-56 - 2019

seer.perspectivasonline.com.br 
DOBBERT, L.Y. Arborização na cidade de Campinas/SP: percepção e conforto. Piracicaba - SP. 2015. 187 f. Tese (Doutorado - Programa Recursos Florestais, Opção em Preservação de Ecossistemas Florestais). Escola Superior de Agricultura "Luiz de Queiroz", Universidade de São Paulo - SP, 2015. Disponível em: <http://bdtd.ibict.br/vufind/>. Acesso em: 19 nov. 2017.

IBGE - Instituto Brasileiro de Geografia e Estatística. Censo Demográfico 2010. Disponível em: <https://censo2010.ibge.gov.br/sinopse/index.php?dados=8>. Acesso em: 17 nov. 2017.

População do município de Campos dos Goytacazes. Disponível em: <https://cidades.ibge.gov.br/brasil/rj/campos-dos-goytacazes/panorama>. Acesso em: 23 set. 2018.

JAMES, R.; MIHELCIC, J. B. Z.; AUER, M. T. Tradução Ramira Maria Siqueira da Silva Pires. Engenharia ambiental: fundamentos, sustentabilidade e projeto. Rio de Janeiro: LTC, 2015.

LOCASTRO, J. K. et al. Avaliação do uso sustentável da arborização urbana no município de Cafeara, Paraná. Ciência Florestal, v. 27, n. 2, p. 549, jun. 2017.

LORENZI, H. Árvores Brasileiras: manual de identificação e cultivo de plantas arbóreas nativas do Brasil. 5 ed. v. 1. Nova Odessa, SP: Instituto Plantarum, 2008. 384p.

Árvores Brasileiras: manual de identificação e cultivo de plantas arbóreas nativas do Brasil. 1 ed v. 3. Nova Odessa, SP: Instituto Plantarum, 2009. 384p.

Árvores Brasileiras: manual de identificação e cultivo de plantas arbóreas nativas do Brasil. 2 ed v. 3. Nova Odessa, SP: Instituto Plantarum, 2009. 384p.

Árvores Brasileiras: manual de identificação e cultivo de plantas arbóreas nativas do Brasil. 4 ed. v. 2. Nova Odessa, SP: Instituto Plantarum, 2013. 384p.

et al. Árvores exóticas no Brasil: madeireiras, ornamentais e aromáticas. Nova Odessa, SP: Instituto Plantarum, 2003. 368p.

OLIVA, G. T. Relação do conforto humano com métricas de cobertura arbórea. 2016. 99 f. Dissertação de mestrado (Programa de Recursos Florestais) - Escola Superior de Agricultura Luiz Queiroz, Universidade de São Paulo - USP, Piracicaba, SP, 2016. Disponível em <http://bdtd.ibict.br/vufind/>. Acesso em: 16 nov. 2017.

PENA, J. C. de C. et al. Street trees reduce the negative effects of urbanization on birds. PLOS ONE, v. 12, n. 3, p. e0174484, 23 mar. 2017.

POTENZA, R. F. Métodos de fórmula para valoração de árvores nas cidades. 2016. $110 \mathrm{f}$. Dissertação de mestrado (escola superior de agricultura Luiz de Queiros) - Universidade de São Paulo, Piracicaba, SP, 2016. Disponível em: <http://bdtd.ibict.br/vufind/> . Acesso em: 19 nov. 2017.

PREFEITURA DO RIO DE JANEIRO. Inventário da Cobertura Arbórea da Cidade do Rio de Janeiro. Rio de Janeiro, 2015. 232p.

Persp. Online: exatas \& eng., Campos dos Goytacazes, 24 (09) 34-56 - 2019 seer.perspectivasonline.com.br 
PREFEITURA DE SÃO PAULO. Secretaria municipal do verde e do meio ambiente. Manual técnico de arborização urbana. 2 ed. São Paulo, 2005. 45p.

Secretaria municipal do verde e do meio ambiente. Manual técnico de arborização urbana. 3 ed. São Paulo, 2015. 121p.

PREFEITURA MUNICIPAL DE CAMPOS DOS GOYTACAZES. Plano diretor do município de Campos dos Goytacazes. Campos dos Goytacazes - RJ, 2008. 122p.

SCHUCH, M. I. S. Arborização urbana: uma contribuição à qualidade de vida com uso das geotecnologias. 2006. $101 \mathrm{f}$. Dissertação de mestrado (Programa de pós-graduação em geomática) - Universidade Federal de Santa Maria, Santa Maria, RS, 2006. Disponível em <http://bdtd.ibict.br/vufind/>. Acesso em: 16 nov. 2017.

SILVA, G. C. D.; NASCIMENTO, M. T. Fitossociologia de um remanescente de mata sobre tabuleiros no norte do estado do Rio de Janeiro (Mata do Carvão). Revista Brasileira de Botânica, v. 24, n. 1, p. 51-62, mar. 2001.

SOUZA, M. S. Arborização urbana e percepção ambiental: uma análise descritiva de dois bairros de Natal - RN. 2008. 98 f. Dissertação de mestrado (Programa de pós-graduação e pesquisa em geografia) - Universidade federal do Rio Grande do Norte - RN, 2008. Disponível em: <http://bdtd.ibict.br/vufind/>. Acesso em: 19 nov. 2017.

VIGNOLIA JUNIOR, R. Vias para arborização da cidade de São Paulo. 2016. 450 f. Tese (Doutorado - Área de concentração: Paisagem e ambiente). Faculdade de arquitetura e urbanismo, Universidade de São Paulo - SP, 2016. Disponível em: <http://bdtd.ibict.br/vufind/>. Acesso em: 31 mar. 2018.

Persp. Online: exatas \& eng., Campos dos Goytacazes, 24 (09) 34-56 - 2019 seer.perspectivasonline.com.br 